Araştırma Makalesi / Research Article, Doğ Afet Çev Derg, 2021; 7(1): 149-158, DOI: 10.21324/dacd.697600

\title{
Siirt İli Deprem Tehlike Analizi
}

\section{Murat Doğruyol ${ }^{1 * \oplus}$}

${ }^{1}$ Siirt Üniversitesi, Mühendislik Fakültesi, Inşaat Mühendisliği Bölümü, 56100, Siirt.

\section{Özet}

Siirt Güneydoğu Anadolu Bölgesinin önemli şehirlerinden biridir. Güneydoğu Anadolu ve çevresindeki diri faylar geçmişte ciddi depremler oluşturmuştur. Bu çalıșmada Doğu Anadolu Fay Zonu (DAFZ) ve Güneydoğu Anadolu Bindirmesi (GAB)'ne bağlı diri fay hatlarının etkilediği bölgede yer alan Şehir merkezi 37.55 kuzey ve 41.56 doğu koordinatlarına sahip Siirt ili merkezinin 200 km yarıçapındaki dairesel alanı çalışma alanı olarak seçilmiştir. Gutenberg-Richter bağıntısı dikkate alınarak bölgenin deprem riski istatistiksel olarak ortaya konulmuştur. Boğaziçi Üniversitesi Kandilli Rasathanesi ve Deprem Araştırma Enstitüsü deprem kataloğundan Gutenberg-Richter bă̆ıntısina en uygun olanı moment magnitüdü (Mw) seçilerek depremlerin aletsel olarak kaydedilmeye başlandığı 1900 yılından 2020 yılına kadar Mw $\geq 4$ gerçekleşen deprem verileri kullanılmıştır. Çalışmada bölgenin magnitüd-frekans ilişkisi, sismik risk ve dönüş periyotları hesaplanmıştır. Buna göre $R^{2}=0.99$, a sabiti 7.0994, $b$ sabiti ise 1.0257 hesaplanmıştır. Yapılan deprem risk analizine göre bölgede 50 yll içerisinde 6.0 ve 6.5 magnitüdde deprem görülme riski sırası ile $\% 79$ ve \%38 olarak; tekrarlanma periyodları ise sırası ile 32 ile 105 yıl olarak hesaplanmıştır. Çalışmanın amacı Siirt ilindeki deprem gerçeğini hatırlatmak, mühendislik yapılarının yeri ve tasarımı yapılırken deprem gerçeğinin unutulmamasıdır.

\section{Anahtar Sözcükler}

Siirt Depremselliği, Gutenberg-Richter Metodu, a ve b Sabiti

\section{Siirt Province Earthquake Hazard Analysis}

\begin{abstract}
Siirt Province is one of the important cities of the Southeastern Anatolia Region. The fault lines around the Southeast Anatolia and surrounding region has caused serious earthquakes on the area. In this study, the study region has been decided as the circular area that is surrounding the $200 \mathrm{~km}$ radius of the city center of Siirt Province. The city center of Siirt stands at 37.55 North and 41.56 East coordinates and is effected by active fault lines connected to the East Anatolian Fault Zone and Southeast Anatolian Thrust. The statistical earthquake risk of the study region has been presented considering Gutenberg and Richter equation. In this study the moment magnitude (Mw) that is most suitable for Gutenberg-Richter Equation has been chosen from Boğaziçi University Kandilli Observatory and Earthquake Research Institute's earthquake catalogue. From the catalogue the earthquake data of Mw $\geq 4$ and between the years 1900-2020 was used. In the study magnitude frequency relation, seismic risk and return periods of the study region have been calculated. According to this $R^{2}=0.99$, a constant has been calculated as 7.0994, $b$ constant has been calculated as 1.0257. According to earthquake risk analysis of the study area the possibility of an earthquake in the next 50 years at the magnitude of 6.0 and 6.5 has been calculated as $\% 79$ and \%38 respectively. While the return periods have been calculated as 32 and 105 years respectively. The purpose of the study is to remind the earthquake risk of the Siirt Province and to make sure earthquake truth of the area won't be forgotten when deciding engineering structures and their location.
\end{abstract}

\section{$\underline{\text { Keywords }}$}

Siirt Seismicity, Gutenberg-Richter, Constant a and b

\section{Giriş}

Depremler sismografların çıkması ile dünyada ilk kez 1880 yılında aletsel olarak kayıt altına alınmaya başlanmıştır. Türkiye'de ise Kandilli Rasathanesinin kurulması ile başlayan süreç 1934 yılında sismografların düzenli olarak kayıt etmesi ile başlamıştır (BDTIM 2018). 1935 yılında Charles Richter, deprem sırasında açığa çıkan enerjinin bir ölçüsü olarak tanımlanan Magnitüd (aletsel büyüklük) depremlerin ölçümünde ve değerlendirilmesinde kullanılan parametrelerin başında gelen kendi adını taşıdığı Richter ölçeği olarak adlandırılan logaritmik bir ölçek geliştirmiştir. Richter ölçeği logaritmik olduğu için hesaplamalarda magnitüdü (M) 4 olan bir depremin yer hareketi 3 M'teki depreminkinden 10 kat daha fazladır. Ancak enerji açısından kıyaslandığında 4 şiddetindeki deprem 3 şiddetindeki depremden 30 kat daha fazla olmaktadır (Gülkan ve Canbay 2008). 
Depremsellik kavramı depremlerin zaman ve uzaydaki dağılımı için kullanılmaktadır. Depremsellikle ile ilgili ilk çalışmalara 1911 yılında Olham ve Ballore tarafından başlandığı bilinmektedir (Purcaru 1975). Ancak Richter Magnitüd Ölçeğinin (Richter 1958) ortaya çıkmasıyla birlikte depremsellik çalışmalarında büyük bir artış sağlanmıştır.

Depremlerin yeri, zamanı ve magnitüd büyüklügü belirsizlik içermektedir. Bunun tespiti için fay hatlarında biriken enerji ve sismik hareketleri saptanarak ya da geçmişte olan depremlerin tarih, yer ve büyüklüğü istatistiksel yöntemler kullanılarak tespit edilebilmektedir. İnşa edilmiş veya edilecek olan mühendislik yapıları için bu belirsizliği ortadan kaldıracak istatistiksel modeller geliştirilmiştir (Celep ve Kumbasar 1996). Bu çalışmada deprem risk analizi istatistiksel modellerden Gutenberg-Richter bağıntısı kullanılmıştır. Bu modele göre Siirt ili merkezinden 200 km yarıçapındaki alanı kapsayan bölgede 1900-2020 yılları arasında gözlenen ve kaydedilen sağlıklı depremlerin magnitüd değerleri ile gelecek on yıllık periyotlarda depremlerin oluşma olasılıkları ve tekrarlanma süreleri tahmin edilebilmektedir.

Türkiye, dünyadaki depremlerin beşte birine kaynaklık eden Akdeniz'den Alpler'e oradan Himalaya'lara kadar uzanan dünyanın en sismik kuşağına köprü vaziyettedir (McKenzie 1972). Bu sismik kuşak Güneydoğu Anadolu Bölgesi'ni etkisi altına almaktadır. En son 1996 yılında yürürlüğe giren Türkiye Deprem Bölgeleri Haritası (TDBH), Afet ve Acil Durum Yönetimi Başkanlığı (AFAD) Deprem Dairesi Başkanlığı tarafından yenilenmiş, 18 Mart 2018 tarih ve 30364 sayılı (mükerrer) Resmi Gazete'de yayımlanmıştır. Yeni harita 1 Ocak 2019 tarihinde yürürlüğe girmiştir. Yeni harita en güncel deprem kaynak parametreleri, deprem katalogları ve yeni nesil matematiksel modeller dikkate alınarak çok daha fazla ve ayrıntılı veriyle hazırlanmıştır. Yeni haritada, bir önceki haritadan farklı olarak deprem bölgeleri yerine en büyük yer ivmesi değerleri gösterilmiș ve "deprem bölgesi” kavramı ortadan kaldırılmıștır. Güncellenen TDBH'na göre Siirt ilinin deprem yer ivmesi 0.245 g'dir. Şekil 1'de Türkiye'nin yeni deprem haritası gösterilmiştir.

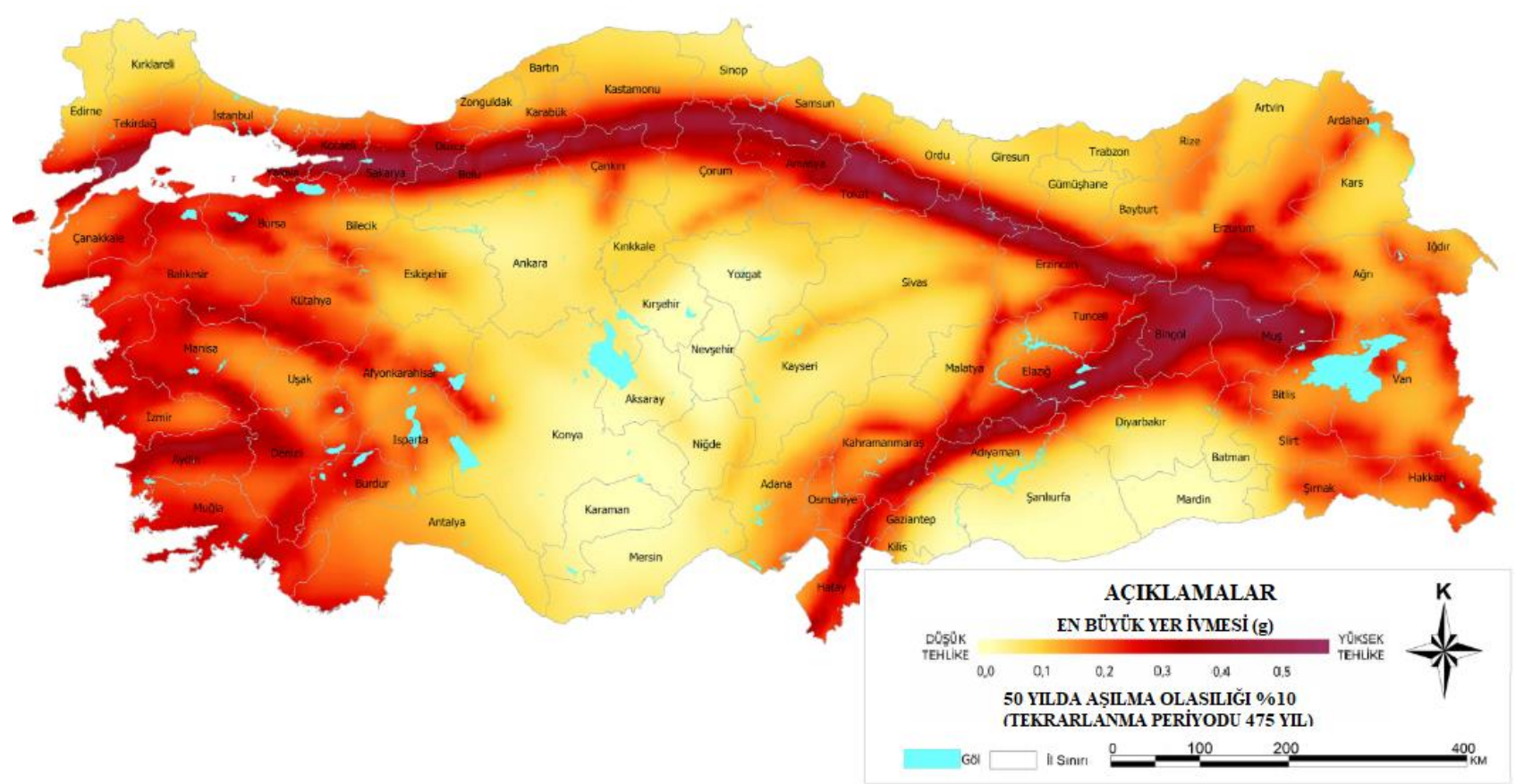

Şekil 1: Türkiye yeni deprem haritası (AFAD 2018)

Siirt ili, Türkiye'nin Güneydoğu Anadolu Bölgesi'nde $41^{\circ}-42^{\circ}$ doğu boylamları ile $37.45^{\circ}-38.15^{\circ}$ kuzey enlemleri arasında yer almaktadır. Siirt ilinin haritadaki yeri Şekil 2’de gösterilmiştir. 


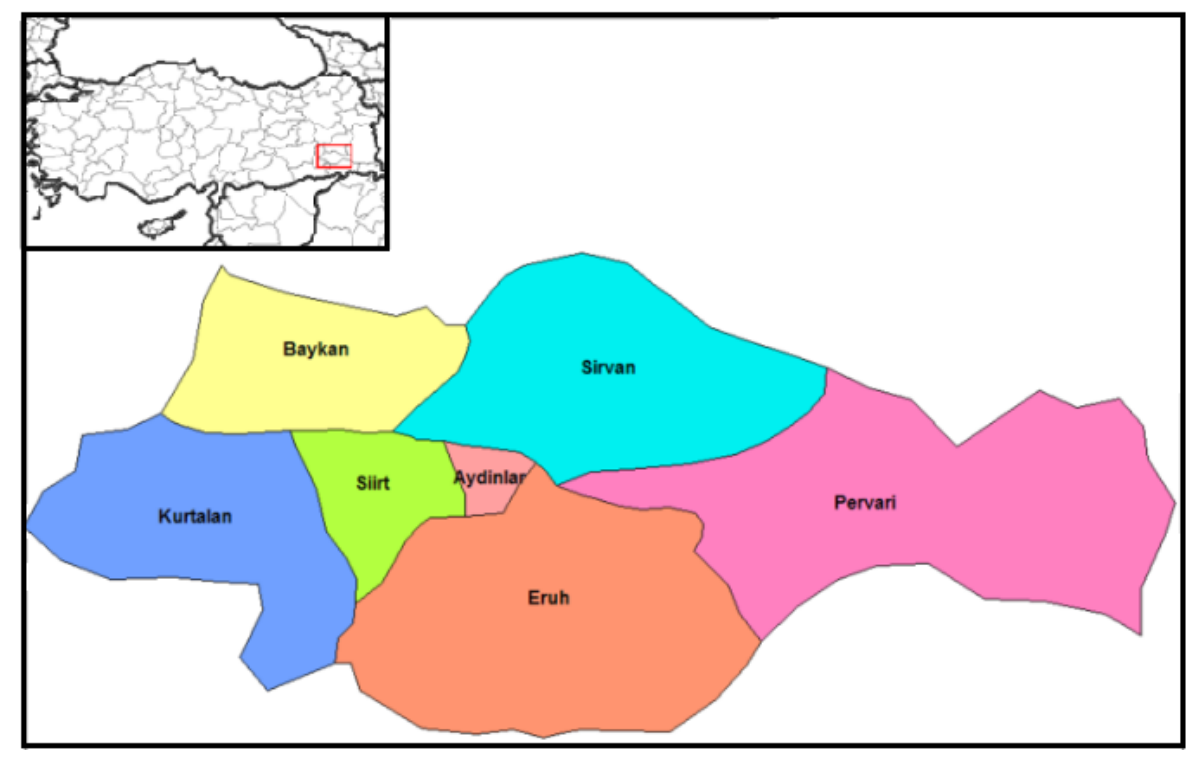

Şekil 2: Siirt ilinin haritadaki yeri

Siirt il merkezinin $200 \mathrm{~km}$ yarıçapındaki alanı çalışma bölgesi olarak belirlenmiş̧ir. Çalışma bölgesi ve çalışma bölgesindeki faylar (siyah çizgiler), diri faylar (kırmızı çizgiler) Şekil 3'de gösterilmiştir (AFAD 2020).

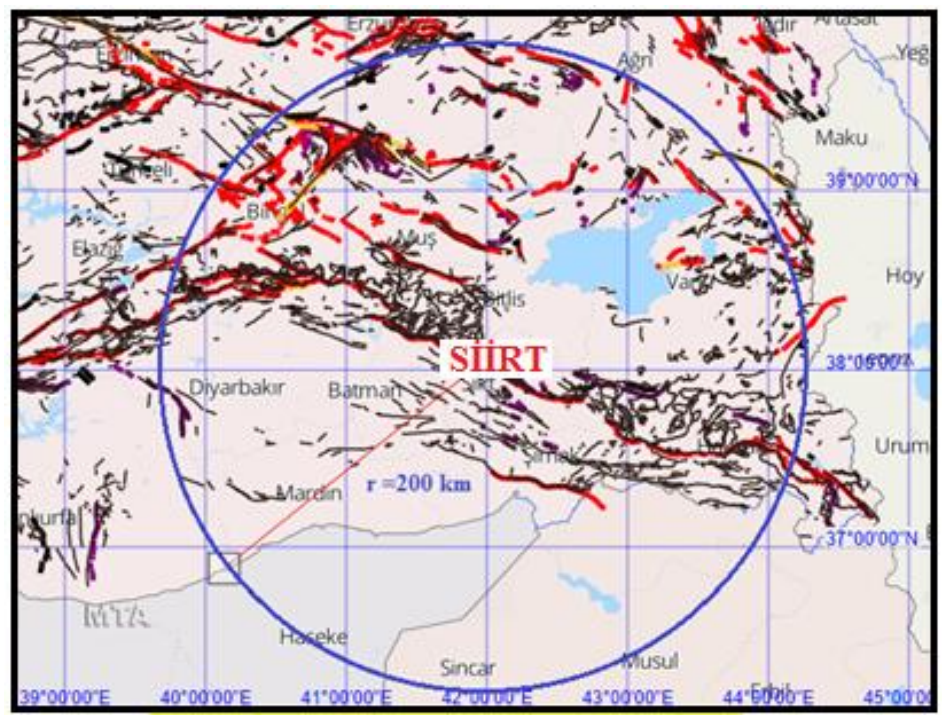

Şekil 3: Çalışma bölgesindeki fay hatları

Yapılan çalışmada AFAD'dan alınan 1900-2020 yılları arası Mw $\geq 4$ gerçekleşen çalışma bölgesi içerisinde kalan Irak ve Suriye'deki depremleri de kapsayan moment magnitüd (Mw) değerleri ile Gutenberg-Richter metodu kullanılarak oluşturulan sismik risk analizidir. Hesaplamalarda depremlerin derinliği ve yeri dikkate alınmadan deprem risk analizi hesaplanmıştır. Bu çalışmadaki amaç geçmişte önemli depremlerin olduğu diri fay zonları ile çevrili Siirt ilinin deprem risk analizi hesaplanarak bölgedeki deprem gerçeğini hatırlatmaktır. Güneydoğu Anadolu'nun DAFZ, GAB gibi diri fay zonları ile çevrili olması bölgede depremsellikle ile ilgi çalışmaların azlığı, 2011 yılında 5.9 Mw'lük Van depreminin yıkıcı etkisi, son olarak 24 Ocak 2020'de Elazığ-Sivrice'de meydana gelen 6.8 Mw depreminin Siirt'i çevreleyen diri fay hatları ile aynı hat kuşağına bağlı olması çalışmanın önemini artırmıştır.

\subsection{Güneydoğu Anadolu Bölgesinin Depremselliği}

Güneydoğu Anadolu Bölgesi'nin etrafı sismik aktivitenin yoğun olduğu Anadolu Plakası ile Arap Plakası arasındaki sınırı oluşturan Doğu Anadolu Fay Zonu (DAFZ), Ölü Deniz Fay Zonu (ÖDFZ) ve Güneydoğu Anadolu Bindirmesi (GAB) ile çevrilmiştir (İmamoğlu ve Çetin 2007). DAFZ Antakya'dan Bingöl Karlıva'ya 580 km uzunluğundaki olup Türkiye'deki en önemli fay zonlarından biridir (McKenzie 1972). ÖDFZ, güneyde Kızıldeniz'den gelerek Reyhanlı'nın kuzeyinden devam eden Narlı yöresinde DAFZ ile birleşen yaklaşık 1000 km uzunluğundaki tektonik kuşaktır. 
ÖDFZ Güneydoğu Anadolu Bölgesi'ni batıdan çevrelemektedir ve geçmişte ağır yıkıcı depremlere kaynaklık etmiştir. GAB Hakkari'den başlayarak Siirt' in kuzeyinden güneybatıya doğru iç bükey bir yay çizerek Kahramanmaraş'ın batısına kadar uzanmaktadır (Şengör 1977). Ayrıca kıtalar çarpışması sınırında gelişen bir yapı olan Güneydoğu Anadolu Bölgesi'nin kuzey kenarı boyunca uzanan Bitlis-Zagros Kenet Kuşağı (BZKK), İran'daki Zagros Bindirme Kuşağı'nın devamı şeklinde olup, doğudan batıya doğru Hakkari, Beytüşşebap, Narlı, Pervari güneyi, Kozluk, Kulp, Lice kuzeyi, Ergani kuzeyi, Çüngüş ve Çelikhan'dan geçer ve bu kuşak bölgedeki önemli depremlere kaynaklık etmiştir (Şekil 3) (Akbaș 1999; İmamoğlu ve Çetin 2007).

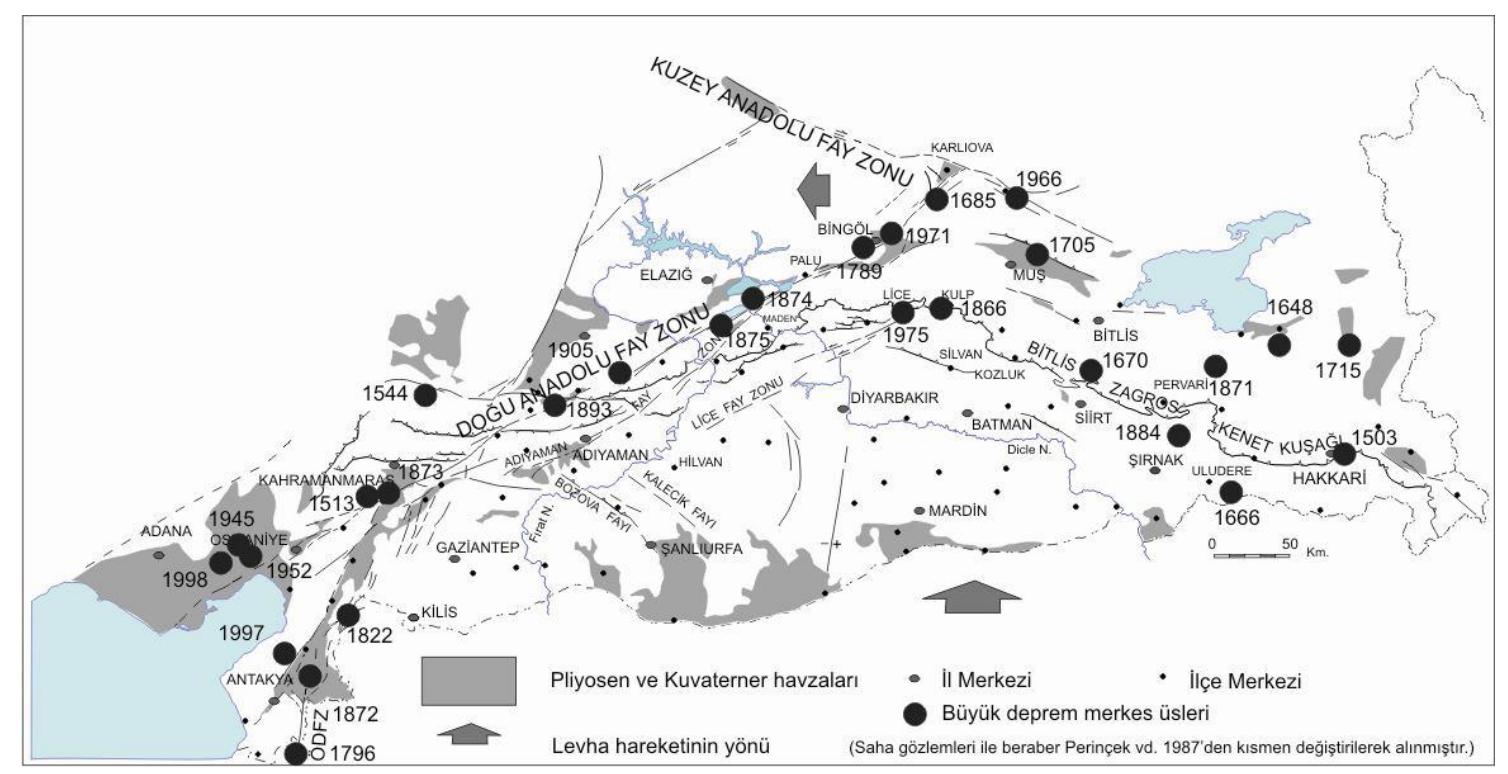

Şekil 4: Güneydoğu Anadolu Bölgesi'ndeki tarihteki büyük depremlerin yeri ve fay haritası

Şekil 4'de gösterildiği gibi Güneydoğu Anadolu Bölgesi ve etrafı, Türkiye'nin en büyük tektonik yapılarından Doğu Anadolu Fay Zonu (DAFZ), Bitlis Zagros Kenet Kuşağı (BZKK), Ölü Deniz Fay Zonu (ÖDFZ) gibi diri fay zonlarının etkisindedir. Bu fayların üzerinde yoğun bir deprem etkinliği bulunmasına rağmen, üzerinde yer alan sismik boşluklardan dolayı bölgenin, özellikle kuzeyde yer alan DAFZ, BZKK ve batıdaki ÖDFZ boyunca, önümüzdeki yüzyıl içinde, tarihi dönemlerde meydana gelen depremlere benzer ve son dönemlerde meydana gelen depremlerden daha büyük depremler olabileceği belirtilmektedir (İmamoğlu ve Çetin 2007; Anadolu ve Kalyoncuoğlu 2010).

Güneydoğu Anadolu Bölgesi'nde tarihin her döneminde sismik hareketlilik yoğun olmuştur. Bölgeyi etkileyen 20. yüzyıl öncesi oluşan bazı büyük depremler Tablo 1'de gösterilmiştir (Sümer 1986; Guidoboni ve Traina 1995; İmamoğlu ve Çetin 2007; Tan vd. 2008; İşçi 2008; Gündoğdu 2009).

Tablo 1: Güneydoğu Anadolu Bölgesini etkileyen 20. yüzyıl öncesi oluşan bazı büyük depremler

\begin{tabular}{|c|c|l|l|l|c|c|}
\hline No & Tarih & Enlem & Boylam & \multicolumn{1}{|c|}{ Bölge } & I & M \\
\hline 1 & 718 & 37.00 & 39.00 & Şanlıurfa & VIII & \\
\hline 2 & 802 & & & Firat Havzas1, Mezopotamya & IX & \\
\hline 3 & 1111 & 38.50 & 42.70 & Ahlat-Van & IX & \\
\hline 4 & 1246 & 38.90 & 42.90 & Van Gölü & IX & \\
\hline 5 & 1276 & 38.90 & 42.50 & Bitlis - Erciş - Van & IX & \\
\hline 6 & 1441 & 38.35 & 42.10 & Nemrut & IX & \\
\hline 7 & 1647 & 39.15 & 44.00 & Van, Muş, Bitlis & IX & \\
\hline 8 & 1666 & & & Halep, Musul, Doğu Anadolu & IX & \\
\hline 9 & 1582 & 38.35 & 42.10 & Bitlis & IX & \\
\hline 10 & 1670 & 38.00 & 42.00 & Hizan-Siirt & & 6.6 \\
\hline 11 & 1705 & 38.40 & 42.10 & Bitlis & 6.7 \\
\hline 12 & 1866 & 38.50 & 40.10 & Kulp - Diyarbakır & & 6.8 \\
\hline 13 & 1874 & & & Diyarbakır, Keban, Malatya & VII & \\
\hline 14 & 1881 & 39.00 & 43.00 & Van, Bitlis, Muş & IX & \\
\hline 15 & 1884 & 37.50 & 42.50 & Siirt - Pervari & VIII & 6.9 \\
\hline
\end{tabular}




\subsection{Siirt İlinin Depremselliği}

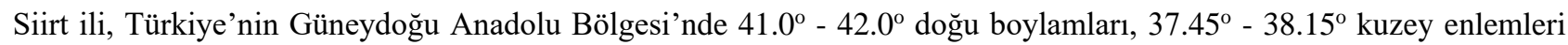
arasında yer alan, $6186 \mathrm{~km}^{2}$ yüz ölçümüne 2018 yılı nüfus verilerine göre 332 bin nüfusa sahiptir. Siirt ili sınırları içerisinde sismik hareketlerin birçoğuna GAB kaynaklık etmiştir. Siirt ili ve çevresindeki depremler kuzeyde Lice, Kozluk, Şirvan ve Hakkari segmentleri, güneyde Görümlü Fayı etkisindedir. Boğaziçi Üniversitesi Kandilli Rasathanesi ve Deprem Araştırma Enstitüsü (BDTIM) verilerine göre 1900-2020 yılları arasında 120 yılda meydana gelen, Siirt ili merkezinden $200 \mathrm{~km}$ yarıçap alan içerisinde kalan alanda derinliği 1-172 km arasında değişen büyüklüğü 4.0- 6.5 magnitüd olan 457 deprem kaydı vardır. Bunların 77'si Mw $\geq 5.0$, 7'si Mw $\geq 6.0$, 2'si de Mw $\geq 6.5$ depremleri oluşturmaktadır. Deprem sayılarını Magnitüd değerlerine göre oranlandığında depremlerin \%60'nı 4.0 M, \%11'ni 5.0 M, $\% 1$ 'ni de 6.0 M depremler oluşturmaktadır. Magnitüd değerlerine göre oluşma yüzdeleri aşağıda Şekil 5'te verilmiştir.

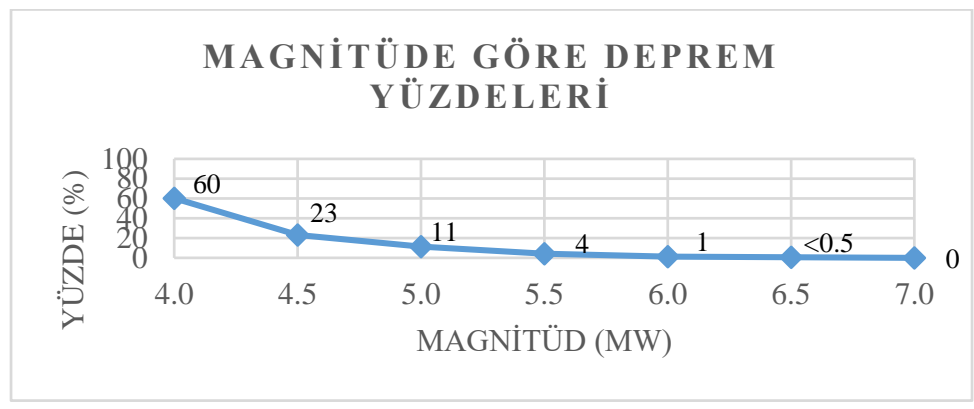

Şekil 5: 1900-2020 yılları arasında Siirt'i etkisi altına alan depremlerin magnitüdlerine göre sıklık dağılım grafiği

Siirt ilinin çevresi diri fay hatları çevrili olmasına rağmen şehir sınırları içerisinde etkili deprem odak noktası bulunmamaktadır (Işı1 2012). Siirt ili etkin DAF ve GAB hatlarına komşu vaziyette bulunduğundan sismik hareketlerin sıklıkla yaşandığı kaydedilmiştir. 1900- 2020 yılları arasında Siirt ili sınırları içerinde Mw $\geq 4$ olan depremlerin yeri ve derinliği Tablo 2'de verilmiştir.

Tablo 2: 1900-2019 Yılları Siirt ili sınırları içerisinde oluşan bazı büyük depremler

\begin{tabular}{|c|l|c|c|c|c|l|}
\hline No & Oluş tarihi & Enlem & Boylam & Derinlik $(\mathbf{k m})$ & Mw & \multicolumn{1}{|c|}{ Yer } \\
\hline 1 & 26.10 .2003 & 37.79 & 42.51 & 11 & 4.1 & Okcular-Pervar1 (Siirt) [8.4 km Kuzeydoğu] \\
\hline 2 & 26.10 .2003 & 37.78 & 42.66 & 5 & 4 & Dugunculer-Pervar1 (Siirt) [11.1 km Kuzeybat1] \\
\hline 3 & 23.10 .2003 & 37.72 & 42.49 & 5 & 4.8 & Okcular-Pervar1 (Siirt) [5.0 km Güneydoğu] \\
\hline 4 & 12.09 .2001 & 37.87 & 42.73 & 5 & 4.2 & Dugunculer-Pervar1 (Siirt) [1.7 km Kuzeybat1] \\
\hline 5 & 14.02 .1995 & 37.75 & 42.96 & 0 & 5.7 & Sar1yaprak-Pervar1 (Siirt) [11.2 km Kuzeydoğu \\
\hline 6 & 02.04 .1984 & 37.62 & 42.88 & 43 & 4.5 & Sar1yaprak-Pervar1 (Siirt) [11.7 km Güneydoğu] \\
\hline 7 & 30.08 .1973 & 37.96 & 42.75 & 45 & 5.0 & Bentkoy-Pervar1 (Siirt) [2.7 km Kuzey] \\
\hline 8 & 15.10 .1929 & 38 & 42 & 30 & 5.2 & Dereyamac-Aydınlar (Siirt) [2.6 km Kuzeybat1] \\
\hline
\end{tabular}

Türkiye'de deprem kayıtları modern olarak 1950'li yıllardan sonra kayıt edildiği için 50'li yıllardan sonra çalışma bölgesinde sismik hareketlerin daha sık olduğu Şekil 5'de görülmektedir (BDTIMM 2019). BDTIM'den alınan verilere göre Siirt ili ve çevresi için $\mathrm{Mw} \geq 4.0$ olan depremlerin yıllara göre dağılımı Şekil 6’da gösterilmiştir.

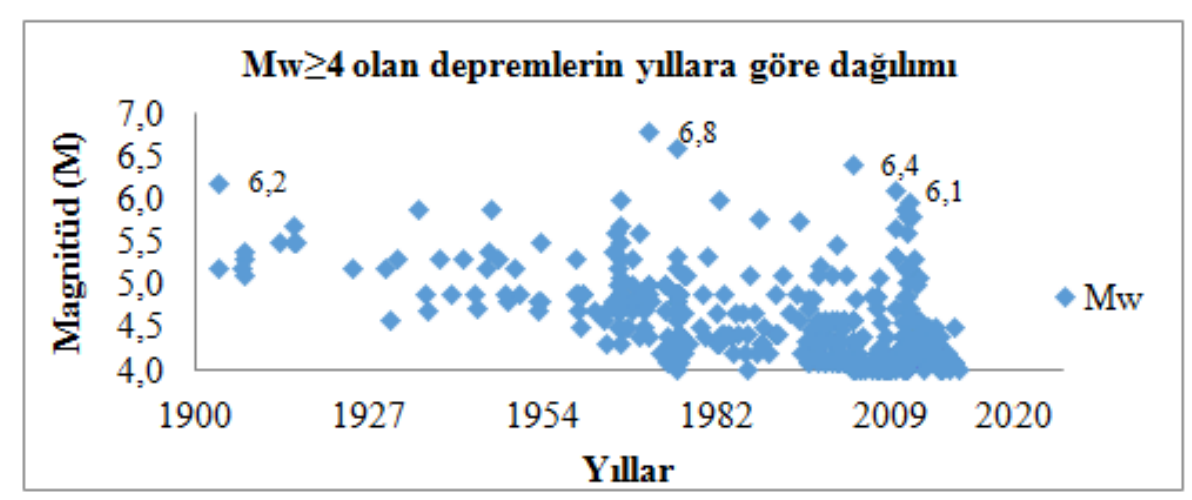

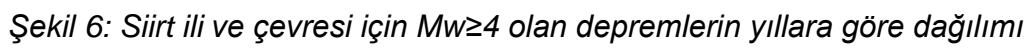


Buna göre $M w \geq 6.0$ 'dan depremlerin yaklaşık 25 yılda 1 tekrarlandığ 1 görülmektedir. Çalışma bölgesinde 1900-2020 yılları arasında depremler ve büyüklükleri Şekil 7a'da, 2018 yılı içerisinde ki depremler ve büyüklükleri Şekil 7b'de gösterilmiştir.

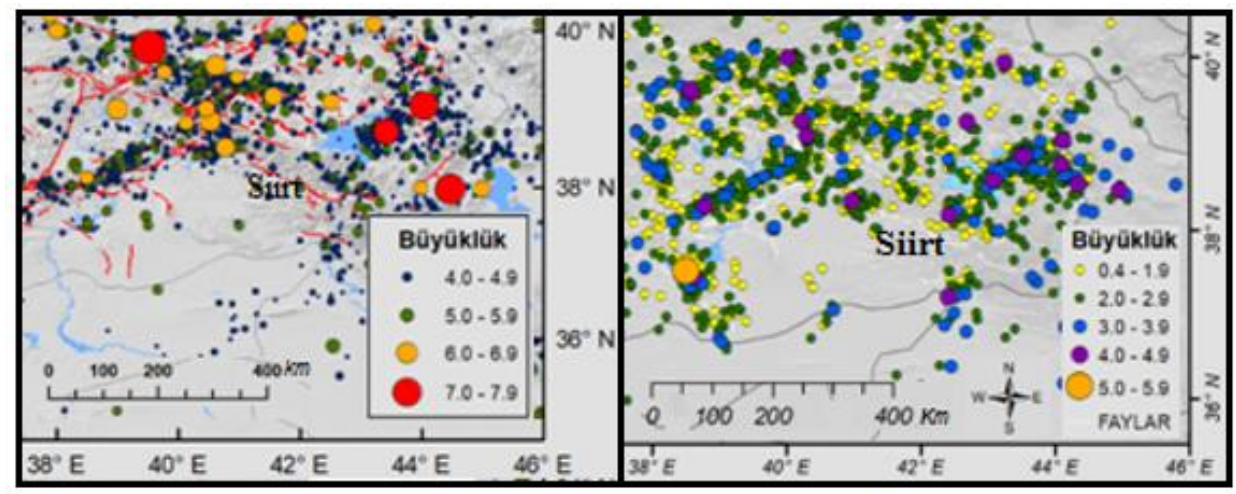

a

b

Şekil 7: Siirt ili merkezinden 200 km yarıçapındaki alan sismik hareketlerin yeri ve büyüklükleri

Tablo 3: 1900-2020 yılları arası Siirt Merkezden 200 km yarıçap alanda oluşan büyük depremler

\begin{tabular}{|c|c|c|c|c|c|c|}
\hline No & Oluş tarihi & Enlem & Boylam & Der (km) & Mw & Yer \\
\hline 1 & 05.08 .2012 & 37.41 & 42.95 & 8.1 & 5.8 & Ortabag-Uludere (Şırnak) \\
\hline 2 & 14.06 .2012 & 37.25 & 42.43 & 9.6 & 5.3 & Yeniköy-Silopi (Şırnak) \\
\hline 3 & 09.11 .2011 & 38.42 & 43.21 & 6 & 5.6 & Edremit (Van) \\
\hline 4 & 23.10 .2011 & 38.63 & 43.08 & 5 & 5.9 & Van Gölü \\
\hline 5 & 08.03 .2010 & 38.83 & 40.13 & 5 & 6.1 & Kovancilar (Elazı̆̆) \\
\hline 6 & 10.12 .2005 & 39.36 & 40.86 & 5 & 5.3 & Kızılçubuk-Karlıova (Bingöl) \\
\hline 7 & 06.06 .2005 & 39.36 & 40.92 & 5 & 5.7 & Ilıpınar-Karlıova (Bingöl) \\
\hline 8 & 23.03 .2005 & 39.39 & 40.80 & 5 & 5.7 & Sarıkuşak-Karlıova (Bingöl) \\
\hline 9 & 14.03 .2005 & 39.35 & 40.88 & 5 & 5.8 & Kazanl1-Karlıova (Bingöl) \\
\hline 10 & 25.03 .2004 & 39.92 & 40.82 & 10 & 5.9 & Kandilli-Aşkale (Erzurum) \\
\hline 11 & 01.05 .2003 & 39.01 & 40.46 & 10 & 6.4 & Kurtuluş (Bingöl) \\
\hline 12 & 03.05 .2002 & 36.99 & 43.35 & 6 & 5.1 & Irak \\
\hline 13 & 15.11 .2000 & 38.28 & 42.94 & 8 & 5.5 & Kurultu-Gevaş (Van) \\
\hline 14 & 03.12 .1999 & 40.23 & 42.21 & 10 & 5.9 & Yukarı horum-Horasan (Erzurum) \\
\hline 15 & 14.02 .1995 & 37.75 & 42.96 & 0 & 5.7 & Sarıyaprak-Pervari (Siirt) \\
\hline 16 & 25.06 .1988 & 38.5 & 43.07 & 49 & 5.7 & Van Gölü \\
\hline 17 & 06.09 .1975 & 38.55 & 40.58 & 47 & 6.1 & Üçdamlar-Lice (Diyarbakır) \\
\hline 18 & 22.05 .1971 & 38.85 & 40.52 & 3 & 7.1 & Guveçl1- (Bingöl) \\
\hline 19 & 23.09 .1968 & 36.49 & 40.68 & 49 & 4.7 & Suriye \\
\hline 20 & 10.08 .1968 & 37.00 & 43.13 & 42 & 5.3 & Irak \\
\hline 21 & 20.08 .1966 & 39.42 & 40.98 & 14 & 5.6 & Kaşıkçı-Karlıva (Bingöl) \\
\hline 22 & 19.08 .1966 & 39.17 & 41.56 & 26 & 6.0 & Çayıryolu-Varto (Muş) \\
\hline 23 & 03.01 .1952 & 39.95 & 41.67 & 40 & 5.8 & Pasinler (Erzurum) \\
\hline 24 & 17.08 .1949 & 39.57 & 40.62 & 40 & 6.5 & Yaylım-Tercan (Erzincan) \\
\hline 25 & 31.05 .1946 & 39.29 & 41.21 & 60 & 5.9 & Kartaldere-Varto (Muş) \\
\hline 26 & 12.11 .1934 & 38.54 & 41.00 & 50 & 5.9 & Dolun-Kulp (Diyarbakır) \\
\hline 27 & 13.09 .1924 & 39.96 & 41.94 & 10 & 6.5 & Emre-Köprüköy (Erzurum) \\
\hline 28 & 14.02 .1915 & 38.8 & 42.50 & 30 & 5.7 & Cemalettin-Ahlat (Bitlis) \\
\hline
\end{tabular}

Çalışma bölgesinin 1900-2020 yılları arasında gerçekleşen büyük depremler Tablo 3’te verilmiştir (BDTIM 2019). Tablo 3'e göre Siirt ili merkezinde 200 km yarıçapını kapsayan alandaki sismik hareketler; Siirt'in güneyinde 2012 yılında Görümlü Fayı etkisinde Şırnak ili Yeniköy-Silopi'de yerden 9.6 km derinlikte 5.3 M, 2010 yılında DAFZ'a bağl1 Palu segmenti kaynaklı Elazığ-Kovancılarda yerin $5 \mathrm{~km}$ derinliğinde 6.1 M,1975'te GAB'a bağlı Lice Segmentinde Diyarbakır-Lice'de yerin 47 metre derinliğindeki 6.1 M, 1971 y1lında Bingöl ili Güveçli'de yerden 3 km derinlikte 6.1 M, 1924 ve 1949 yıllarında ise Erzurum- Köprüköy ve Erzincan- Tercan'da 6.5 M gibi büyük depremler çalışma alanın sismisitesinin ne kadar aktif olduğunu göstermektedir. 
Haziran 2012'de Silopi Yeniköy'de gerçekleşen 5.3 M depremde merkezde can kaybı yaşanmadığı, hastane ve kamu binalarının hasar almadığ 1 ancak merkez caminin minaresinin yıkıldığı kırsalda bazı ev ve ahırların hasar aldığı rapor edilmiştir (MTA 2012). AFAD kaynaklarına göre 1971 yılında Bingöl Güveçli'de 6.1 M depremin yüzey çatlaklarına neden olduğu kayıtlara geçmiştir. Deprem Bingöl'de ağır hasara sebep olmuş birçok kişinin hayatını kaybetmesine; yı̆̆ma, kerpiç, betonarme yapıların ağır hasar almasına neden olmuştur.

\section{Materyal ve Metot}

Çalışma bölgesinde son 120 yıldaki $\mathrm{M} \geq 4$ olan 457 düğüm noktası için deprem verileri Magnitüd-Frekans dağılımı için en yaygın olarak bilinen eşitlik Gutenberg ve Richter bağıntısı dikkate alınarak bölgenin deprem riski istatistiksel olarak ortaya konulmuştur. Gutenberg ve Richter (1944) bağıntısına göre;

$$
\log N=a-b M
$$

Denklem (1)'de ki gibi ifade edilmektedir. Burada N verilen bir bölge ve periyot için magnitüdü M'e eşit veya daha büyük olan depremlerin sayısını. a ve b ise regresyon katsayılarını göstermektedir (Dowrick 2003). a parametresi inceleme alanına genişliğine ve deprem düzeyine bağlı iken $b$ değeri ise bölgenin depremselliğine bağlı değişen parametredir. $b$ değeri bölgeden bölgeye kabaca \pm 0.3 arasında değişim gösterir. b-değerindeki değişimlerin küçük ve büyük depremlerin rölatif oranı kırıklı ortamın heterojenite derecesi jeolojik yapı yamulma ve gerilme gibi bölgesel koşullara bağlı olduğu ve ayrıca ortalama b-değerinin bölgesel olarak 1.0'e eşit olduğu ifade edilmiştir (Frohlich ve Davis 1993). b değeri arttıkça bölgenin sismisitesinin yüksek olduğunu göstermektedir (Hatzidimitriou vd. 1985; Wiemer ve Wyss 1997; Kijko 1988; Wiemer vd. 1998; Papazachos 1974; Papazachos 1999). Gutenberg ve Richter (1954) dünya ölçüsünde istatistik sonuçlara dayanarak sı̆̆ depremler için $b=0.9 \pm 0.02$. orta ve derin depremler için $b=1.2 \pm 0.2$ değerlerini bulmuşlardır. Türkiye için b=0.9 \pm 0.2 değerini, Güneydoğu Anadolu Bölgesi için b değeri $b=1.0 \pm 0.2$ vermektedir (Anadolu ve Kalyoncuoğlu 2010).

Gutenberg-Richter metodunda öncü ve artçı depremler ayıklanmadan Boğaziçi Üniversitesi Kandilli Rasathanesi ve Deprem Araştırma Enstitüsü tarafından alınmış deprem verileri kullanılmıştır. Deprem kayıtlarında moment magnitüdü $\left(\mathrm{M}_{\mathrm{W}}\right)$, yerel magnitüd $\left(\mathrm{M}_{\mathrm{L}}\right)$, süre magnitüdü $\left(\mathrm{M}_{\mathrm{d}}\right)$, yüzey dalga magnitüdü $\left(\mathrm{M}_{\mathrm{S}}\right)$, cisim dalga magnitüd $\left(\mathrm{M}_{\mathrm{b}}\right)$ gibi 5 farklı magnitüd büyüklüğü yer almaktadır. Katalogda yer alan magnitüd verileri tek bir magnitüd ölçeğine çevrilmesi önemlidir. Gutenberg-Richter metodu uygulanması üzere $\mathrm{M}_{\mathrm{W}}$ verileri kullanılması uygun olacaktır. $\mathrm{M}_{\mathrm{w}}$ verilerinin kayıt edilmediği verilerde diğer magnitüd verilerinin aşağıdaki dönüşüm metotları uygulanarak çevrilmiştir (Boore ve Joyner 1982; Ulusay vd. 2004).

$$
\begin{aligned}
& M_{W}=2.25 * M_{b}-6.14 \\
& M_{w}=1.27 * M_{d}-1.12 \\
& M_{W}=0.54 * M_{S}+2.81 \\
& M_{W}=1.57 * M_{L}-2.66
\end{aligned}
$$

Mw deprem verileri magnitüd sayılarına göre frekansları belirlenmiştir. Daha sonra yığınsal frekanslar hesaplanarak Log N değerleri hesaplanmıştır. Doğrusal regresyon ile magnitüd - Log N ilişkisinin en küçük kareler yöntemi ile a ve b parametreleri hesaplanmıştır. Doğrusal regresyon ile daha emniyetli değerler elde edilmiştir.

\section{Bulgular}

Siirt ili merkezden $200 \mathrm{~km}$ yarıçap alınarak oluşturulan alanda $\mathrm{M} \geq 4$ olan depremler dikkate alınarak Tablo 4'te Gutenberg-Richter bağıntısındaki Log N hesaplanmıştır.

Tablo 4: Deprem magnitüd değerlerinin logaritmik değerleri

\begin{tabular}{|c|c|c|c|c|c|}
\hline $\mathbf{M}$ & Ort.Aralık & Frekans & Log N & Yığınsal Frekans & Log N \\
\hline $4.0-4.5$ & 4.25 & 268 & 2.43 & 455 & 2.66 \\
\hline $4.5-5.0$ & 4.75 & 126 & 2.10 & 187 & 2.27 \\
\hline $5.0-5.5$ & 5.25 & 43 & 1.63 & 61 & 1.79 \\
\hline $5.5-6.0$ & 5.75 & 14 & 1.15 & 18 & 1.26 \\
\hline $6.0-6.5$ & 6.25 & 3 & 0.48 & 4 & 0.60 \\
\hline $6.5-7.0$ & 6.75 & 1 & 0.00 & 1 & 0.00 \\
\hline
\end{tabular}


Tablo 4'te yer alan yığınsal frekans ile sismolojide verilen bir M magnitüdüne eşit veya daha büyük olan depremlerin sayısı anlaşılabilir. Yı̆ğınsal frekans ile Log N değeri ile Gütenberg-Richter bağıntısı Şekil 8'de gösterilmiştir.

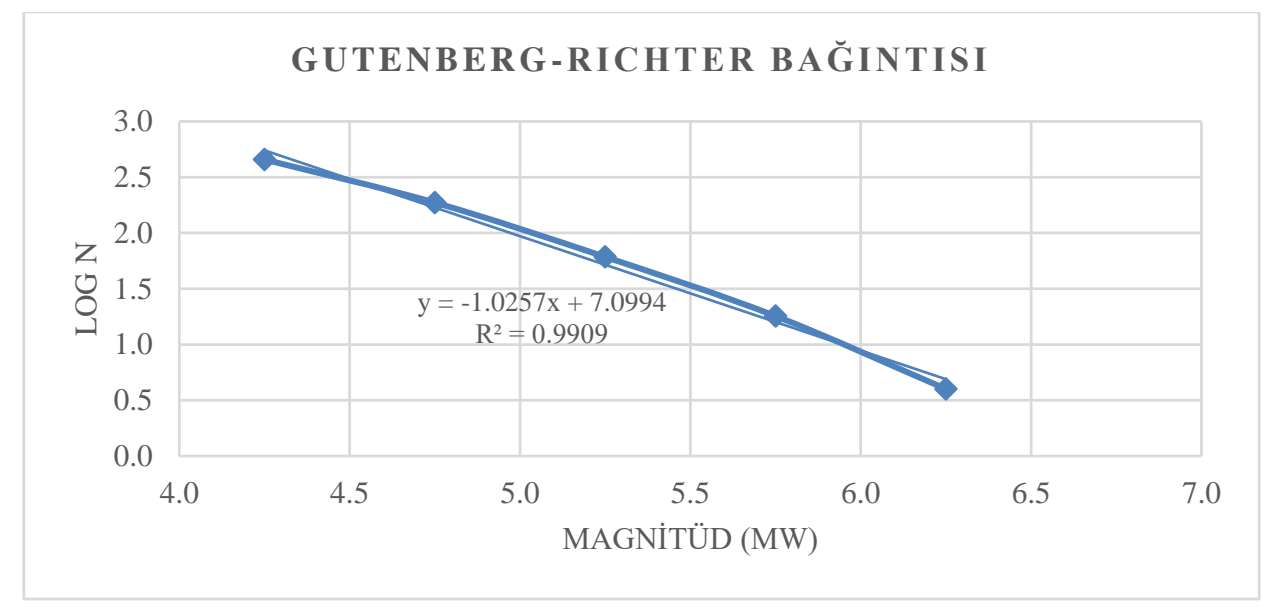

Şekil 8: Gutenberg-Richter bağıntısı en küçük kareler metodu

Şekil 8'de Gutenberg- Richter bağıntısında a ve b parametrelerinin bulunması için en küçük kareler metodu uygulanarak $\mathrm{R}^{2}=0.99$ düzeyinde korelasyon katsayısı ile değişkenler arasındaki kuvvetli ilişki belirlenmiştir. GütenbergRichter bağıntısı:

$\log N=7.0994-1.0257 M$

olarak bulunmuştur. Denklem (6)'ya göre Regrasyon analizinde a parametresi 7.0994, b parametresi 1.0257 olarak hesaplanmıştır. a ve b parametreleri kullanılarak incelen bölgenin depremselliğini belirten parametreler şu şekilde hesaplanmaktadır.

$a^{\prime}=a-\log (b \ln 10)$

$a_{1}=a-\log T$

$a_{1}^{\prime}=a^{\prime}-\log T$

Bulunan katsayıları,

$n(M)=10^{\left(a 1^{\prime}-b M\right)}$

Denklem (10)'da kullanarak depremlerin yıllık oluş sayıları hesaplanmaktadır. Belirli bir magnitüd değerinin T yıl içinde oluşma riski denklem (11)'de hesaplanmıştır;

$R(M)=1-e^{-n(M) T}$

Oluşan depremin tekrarlanma periyodu ise;

$Q=\frac{1}{n(M)}$

bağıntısı kullanılarak hesaplanmıştır. Buna göre deprem tehlikesini belirlemede kullanılan parametre değerleri Tablo 5 'te gösterilmiştir.

Tablo 5: Deprem tehlikesini belirlemede kullanılan parametreler

\begin{tabular}{|c|c|c|c|c|}
\hline $\mathbf{a}$ & $\mathbf{b}$ & $\mathbf{a} 1$ & $\mathbf{a}^{\prime}$ & $\mathbf{a}^{\prime}$ \\
\hline 7.0994 & 1.0257 & 5.02022 & 6.72616 & 4.64698 \\
\hline
\end{tabular}


Tablo 5'te elde edilen parametreler çalışma bölgesinin sismik risk analizinde kullanılmıştır. Buna göre çalışma alanın 10 yıllara göre farklı magnitüd (M) büyüklüğündeki depremlerin oluşma olasılıkları (\%) ve tekrarlanma periyotları (Q) Tablo 6'da gösterilmiştir.

Tablo 6: Yıllara göre sismik risk

\begin{tabular}{|c|c|c|c|c|c|c|c|c|c|c|c|c|}
\hline \multirow{3}{*}{$\mathbf{M}$} & \multirow{3}{*}{$\mathbf{n}(\mathbf{M})$} & \multicolumn{10}{|c|}{ SİSMİK RİSK } & \multirow{3}{*}{$\mathbf{Q}$} \\
\hline & & \multicolumn{10}{|c|}{ YILLAR } & \\
\hline & & 10 & 20 & 30 & 40 & $\mathbf{5 0}$ & 60 & 70 & 80 & 90 & 100 & \\
\hline & & & & & & $\%$ & & & & & & \\
\hline 4.0 & 3.5009 & 100 & 100 & 100 & 100 & 100 & 100 & 100 & 100 & 100 & 100 & 0.3 \\
\hline 4.5 & 1.0748 & 100 & 100 & 100 & 100 & 100 & 100 & 100 & 100 & 100 & 100 & 0.9 \\
\hline 5.0 & 0.3300 & 96 & 100 & 100 & 100 & 100 & 100 & 100 & 100 & 100 & 100 & 3.0 \\
\hline 5.5 & 0.1013 & 64 & 87 & 95 & 98 & 99 & 100 & 100 & 100 & 100 & 100 & 9.9 \\
\hline 6.0 & 0.0311 & 27 & 46 & 61 & 71 & 79 & 85 & 89 & 92 & 94 & 96 & 32.2 \\
\hline 6.5 & 0.0095 & 9 & 17 & 25 & 32 & 38 & 44 & 49 & 53 & 58 & 62 & 104.7 \\
\hline 7.0 & 0.0029 & 3 & 6 & 8 & 11 & 14 & 16 & 19 & 21 & 23 & 25 & 341.1 \\
\hline
\end{tabular}

Tablo 6'da elde edilen sismik risk analizine göre çalışma bölgesinde farklı magnitüd seviyelerinin tekrarlanma zamanları Şekil 9a'da, yıl içinde oluşma olasılıkları Şekil 9b'de gösterilmiştir.

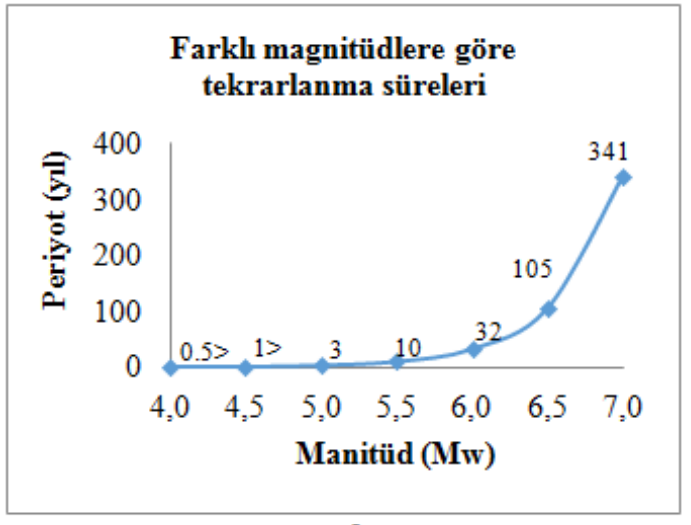

a

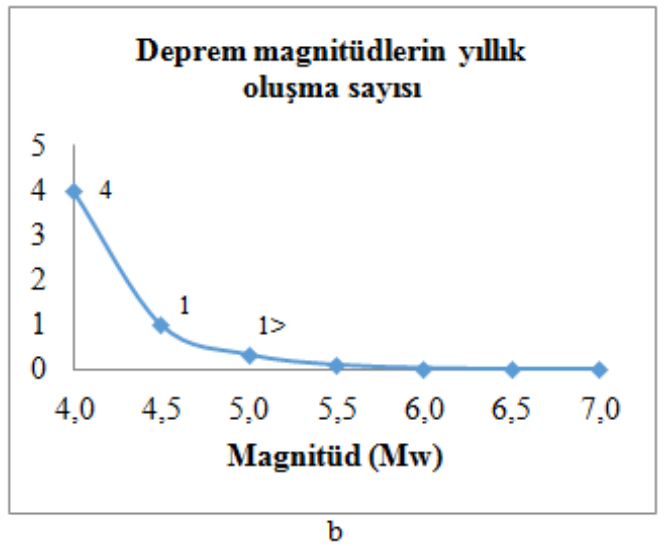

Şekil 9: Farklı magnitüd değerlerine göre a) tekrarlanma zamanları b) yıllık oluşma olasılıkları

\section{Sonuç}

Bu çalışmada Siirt ili ve çevresinin (37.55 kuzey ve 41.56 doğu koordinatlarının $200 \mathrm{~km}$ çevresi) depremselliği ve deprem riski incelenmiştir.

BDTIMM tarafından alınmış katalogdan çalışma bölgesinde 120 yıllık geçmiş deprem magnitüd değerleri ile $\mathrm{M}_{\mathrm{w}}$ magnitüd skalası kullanılarak Gutenberg- Richter bağıntısı ile magnitüd-frekans ilişkisi ve yüzyıl boyunca onar yıllık sismik riski hesaplanmıştır. Buna göre $\mathrm{R}^{2}=0.99$ korelasyon a sabiti 7.09. b sabiti ise 1.02 hesaplanmıştır. b sabitine göre bölgenin depremselliğinin fazla olduğunu söyleyebiliriz. Yapılan deprem risk analizine göre Bölgede 50 yıl içerisinde 6 ve 6.5 büyüklüklerinde deprem görülme riski sırası ile \% 79 ve \%38 olarak, tekrarlanma periyodları ise sırası ile 32 yıl ile 105 yıl olarak hesaplanmıştır. Ayrıca $4 \mathrm{M}$ depremin yıl içinde tekerrür periyodu 4 iken $4.5 \mathrm{M}$ deprem yıl içinde tekerrür periyodu 1 olarak hesaplanmıştır.

Mw>6'dan depremlerin yaklaşık 25 yılda 1 tekrarlandığı, bu büyüklükteki en depremin en son 1971 ve 1975 'te yıllarında Bingöl Güveçli ve Lice Diyarbakır'da kaydedilmiştir. Ancak bölgede 20. yüzyıl öncesi sismik kayıtlar incelendiğinde $6.5<\mathrm{Mw}<7.0$ depremlerin yaklaşık 100 yılda 1 tekerrür ettiği kaydedilmiştir. Deprem kayıtlarından en son 1884 yılında Siirt-Pervari’de 6.9 büyüklüğündedir.

Siirt'in depremselliğini belirlemek için sadece istatistiksel yöntemler değil arazide yerinde gözlem ve araştırma yapmak gereklidir. Amaç bilimsel veriler doğrultusunda can ve mal güvenliğini en üst seviyeye taşımak olmalıdır.

Siirt kuzeyinde aktif GAB fayı güneyinde aktif Cizre fayının etkisi ile sismik hareketlerin sık olduğu Siirt merkezde özellikle alüvyon zemine sahip Kezer çayı etrafının deprem etkisinin fazla hissedileceği bölgedeki yapılarda yapı zemin ilişkisinin iyi tasarlanması gerektiği mevcut yapı stokunun yorgun, eski ve bitişik nizam yapıların risk altında olabileceği unutulmamalıdır. 


\section{Kaynaklar}

AFAD, (2018), Türkiye Deprem Tehlike Haritasl, https://deprem.afad.gov.tr/deprem-tehlike-haritasi [Erișim 06 Ocak 2020].

AFAD, (2020), AFAD son depremler, http://www.deprem.gov.tr/sarbis/Shared/Default.aspx [Erişim 11 Şubat 2020].

Akbaş Ö., (1999), 27 Haziran 1998 Adana-Ceyhan depremi fay mekanizması, Deprem Araştırma Bülteni, 26(80), 5-108.

Anadolu N., Kalyoncuoğlu Ü., (2010), Güneydoğu Anadolu bölgesinin depremselliği ve deprem tehlike analizi, Süleyman Demirel Üniversitesi, Fen Bilimleri Enstitüsü Dergisi, 14(1), 84-94.

BDTIM, (2018), Geçmişten günümüze Kandilli Rasathanesi ve Deprem Araştırma Enstitüsü, http://www.koeri.boun.edu.tr/new/tr/ tarihce, [Erişim 06 Ocak 2020].

BDTIM, (2019), Kandilli Rasathanesi BDTIM Deprem Sorgulama Sistemi, http://www.koeri.boun.edu.tr/sismo/zeqdb/default.asp [Erişim 03 Şubat 2020].

Boore D.M., Joyner W.B., (1982), The empirical prediction of ground motion, Bulletin of the Seismological Society of America, 72(6), 43-60.

Celep Z., Kumbasar N., (1996), Yapı dinamiği ve deprem mühendisliğine giriş, Sema Matbaacılık, İstanbul.

Dowrick D.J., (2003), Earthquake risk reduction, John Wiley \& Sons, Chichester, UK, 520ss.

Frohlich C., Davis S., (1993), Teleseismic b-values: or. much abouth 1.0., Journal of Geophysical Research: Solid Earth, 98(B1), 631644.

Guidoboni E., Traina G., (1995), A new catalogue of earthquakes in the historical Armenian area from antiquity to the 12th century, Analı DiGeofisica, 38(1), 85-111.

Gutenberg B., Richter C.F., (1944), Frequency of earthquakes in California, Bulletin of the Seismological Society of America, 34(4), $185-188$.

Gutenberg B., Richter C.F., (1954), Earthquake magnitude, intensity, energy and acceleration, Bulletin of the Seismological Society of America, 63, 501-516.

Gülkan P., Canbay E., (2008), Binalar için deprem mühendisliği temel ilkeler, ODTÜ Geliştirme Vakfı Yayıncılık, 1. Baskı, 1-15, Ankara.

Gündoğdu O., (2009), Van ve çevresinin deprem tehlikesi, Van Kent Sempozyumu, TMMOB Van İl Koordinasyon Kurulu, 01-03 Ekim, Van. ss. 97-116.

Hatzidimitriou P.M., Papadimitriou E.E., Mountrakis D.M., Papazachos B.C., (1985), The seismic parameter b of the frequencymagnitude relation and its association with the geological zones in the area of Greece, Tectonophysics, 120(1-2), 141-151.

Işık E., (2012), Siirt Illi'nin Deprem Tehlikesi, Dicle Üniversitesi Fen Bilimleri Dergisi, 1(1), 29-38.

İmamoğlu M.Ş., Çetin E., (2007), Güneydoğu Anadolu bölgesi ve yakın yöresinin depremselliği, Dicle Üniversitesi Ziya Gökalp Eğitim Fakültesi Dergisi, 9(2007), 93-103.

İşçi Ç., (2008), Deprem nedir ve nasıl korunuruz? Journal of Yasar University, 3(9), 959-983.

Kijko A., (1988), Maximum likelihood estimation of Gutenberg-Richter b parameter for uncertain magnitudes values, Pure Appl. Geophys, 127(4), 573-579.

Mckenzie D., (1972), Active tectonics of the Mediterranean region, Geophysical Journal of the Royal Astronomical Society, 30(2), 109-185.

MTA (2012), 14 Haziran 2012 Silopi (Şırnak) Depremi Değerlendirme Notu, Maden Tetkik ve Arama Genel Müdürlüğü Jeoloji Etütleri Dairesi Başkanlığı Yer Dinamikleri Araştırma ve Değerlendirme Koordinatörlüğü, Ankara, 5ss.

Papazachos B.C., (1974), Dependence of the seismic parameter b on the magnitude range, Pure and Applied Geophysics, 112(6), 10591065.

Papazachos B.C., (1999), An alternative method for a reliable estimation of seismicity with an application in Greece and the surrounding area, Bulletin of the seismological society of America, 89(1), 111-119.

Purcaru G., (1975), A new quantitative measure of seismicity and some related problems, Veröff. Zentralinst. Physikd. Erde Nr. 31. Teil. 1, 185-204.

Richter C.F., (1958), Elementary seismology, WH Freemanand Co., San Francisco.

Sümer F., (1986), Ahlat Şehri ve Ahlatşahlar, Belleten, Türk Tarih Kurumu, 50, 197. Ankara.

Șengör A.M.C., (1977), New Historical Data on Crustal Subduction, The Journal of Geology, 85(5), 631-634.

Tan O., Tapırdamaz M.C., Yörük A., (2008), The Earthquake Catalogues For Turkey, Turkish Journal of Earth Sciences, 17(2), 405418.

Ulusay R., Tuncay E., Sonmez H., Gokceoglu C., (2004), An Attenuation relationship based on Turkish strong motion data and isoacceleration map of Turkey, Engineering Geology, 74(3-4), 265-291.

Wiemer S., Mcnutt S.R., Wyss M., (1998), Temporal and Three-Dimensional Spatial Analysis of the Frequency-Magnitude Distributions Near Long Valley Caldera, Geophysical Journal International, 134(2), 409-421.

Wiemer S., Wyss M., (1997), Mapping The Frequency-Magnitude Distributions in Asperities: An Improved Technique to Calculate Recurrence Times, Journal of Geophysical Research: Solid Earth, 102(B7), 15115-15128. 